\title{
Metamorfoses na avaliação em Educação Física: da formação inicial à prática pedagógica escolar
}

\author{
Evandra Hein Mendes* \\ Juarez Vieira do Nascimento** \\ José Carlos Mendes ${ }^{* * *}$
}

\begin{abstract}
Resumo: O processo de estruturação da prática pedagógica e especificamente das práticas avaliativas em Educação Física, pode sofrer influências tanto das experiências vivenciadas com a avaliação no ensino fundamental e médio, quanto àquelas advindas do curso de formação inicial ou ainda com o ingresso no mercado de trabalho e o impacto com a cultura docente já instalada. Nessa perspectiva, esta investigação analisou o processo de estruturação das práticas avaliativas na Educação Física escolar. Os resultados revelaram o fraco impacto da formação inicial no processo de estruturação das práticas avaliativas, sendo mais determinante a experiência profissional advinda da própria realidade educacional.
\end{abstract}

Palavras-chave: Avaliação. Aprendizagem. Educação Física. Docentes. Prática profissional.

\section{INTRODUÇÃO}

O processo de implementação das práticas avaliativas na intervenção pedagógica de professores de Educação Física, em todos os níveis de ensino, é cercado de dúvidas e contradições caracterizando-se como elemento gerador de inúmeras reflexões e discussões sobre o assunto.

As principais discussões dizem respeito tanto à forma reducionista, autoritária, classificatória e quantitativa dos sistemas de avaliação já instituídos, quanto à compreensão da avaliação apenas como um produto final da aprendizagem escolar.

No que se refere à construção dos documentos oficiais destinados à educação, as Leis de Diretrizes e Bases da Educação Nacional

\footnotetext{
* Professora mestre da Universidade Estadual do Oeste do Paraná (UNIOESTE). E-mail: evandra@unioeste.br

** Professor doutor da UFSC. Coordenador dos cursos de Mestrado e Doutorado em Educação Física da UFSC. E-mail: juarezvn@cds.ufrsc.br

*** Professor mestre da Uniguaçu/Faesi. E-mail: josemendes@faesi.com.br
} 


\section{Astifor Originais}

Evandra Hein Mendes, et al.

(LDB), a partir da Lei 9.394/96 propõem no seu artigo 24 um modelo de avaliação com caráter contínuo e cumulativo, com prevalência dos aspectos qualitativos sobre os quantitativos e dos resultados adquiridos ao longo do período sobre as eventuais provas finais.

Em contrapartida, as características das práticas avaliativas implementadas pelos professores de Educação Física na atualidade, identificadas pelos estudos de Bratifische (2003) e Souza (1993), tanto no ensino fundamental e médio, quanto no superior, direcionase na maioria das vezes exclusivamente à verificação do aprendizado pela análise da capacidade de retenção de informações e reprodução de movimentos técnicos, desconsiderando-se o desenvolvimento e progresso global do aluno.

O processo de avaliação é construído pelo professor a partir de suas vivências com as práticas avaliativas utilizadas por professores, quanto discussões relacionadas ao tema.

Nesta perspectiva, este estudo procurou analisar o processo de estruturação das práticas avaliativas implementadas na Educação Física Escolar pelos egressos do curso de Educação Física da UNIOESTE - Universidade Estadual do Oeste do Paraná.

\section{PROCEDIMENTOS METODOLÓGICOS}

Tendo em vista o tema da investigação, idealizou-se uma pesquisa qualitativa, com o intuito de subsidiar as discussões de forma a não limitar as dimensões de análise e o próprio campo de observação, já que conforme Bogdan e Biklen (1994), os investigadores qualitativos acreditam que as situações são complexas; sendo assim, tentam descrever muitas dimensões e não restringir o campo de observação.

O mundo real desta investigação foi composto por um curso de formação inicial em Educação Física e estabelecimentos de ensino fundamental e médio do município de Marechal Cândido Rondon, Paraná.

Neste contexto, os sujeitos participantes foram professores egressos do curso de formação inicial em Educação Física da UNIOESTE, que se encontravam imersos no tema da investigação,

Movimento, Porto Alegre, v.13, n. 02, p.55-76, maio/agosto de 2007. 
por constituírem a realidade educacional do ensino fundamental, médio e superior deste município.

Quanto à seleção dos participantes egressos do curso de graduação em Educação Física da UNIOESTE, ela foi intencional e se realizou mediante o cumprimento do critério de ser atuante no ensino fundamental e médio há pelo menos dois anos no município de Marechal Cândido Rondon, Paraná. Este critério foi adotado por se acreditar que o tempo de atuação profissional de dois anos se constitua o tempo mínimo para que um profissional obtenha subsídios para as constantes tomadas de decisões que o cotidiano da prática pedagógica exige.

Compreendida como essencial, a etapa inicial de caracterização dos participantes da investigação apresentou informações em relação ao gênero, a idade, o estado civil, a área de formação, a titulação, o regime de trabalho e os anos de experiência profissional (Tabela 1).

Tabela 1: Perfil dos participantes da investigação

\begin{tabular}{lll}
\hline Características & \multicolumn{1}{c}{$\begin{array}{c}\text { Professores } \\
\text { Egressos }\end{array}$} & Frequiência \\
\hline \multirow{2}{*}{ Gênero } & $\begin{array}{l}\text { Masculino } \\
\text { Feminino }\end{array}$ & 3 \\
& $25-30$ anos & 2 \\
Idade & $31-35$ anos & 4 \\
& $36-40$ anos & 2 \\
\hline Estado Civil & Casados & 8 \\
\hline Área de formação & Licenciatura em EF & 8 \\
\hline \multirow{2}{*}{ Titulação } & Graduados & 4 \\
\hline \multirow{2}{*}{ Regime de } & Especialistas & 4 \\
trabalho & $11-10$ aulas 20 aulas & 1 \\
& $21-30$ aulas & 1 \\
\hline Anos de & $31-40$ aulas & 5 \\
experiência & $0-10$ anos & 4 \\
\hline
\end{tabular}

Movimento, Porto Alegre, v.13, n. 02, p.55-76, maio/agosto de 2007. 
O grupo caracterizou-se como jovem, com predominância do gênero feminino, sendo que todos eram casados. $\mathrm{Na}$ análise da titulação, todos eram licenciados em Educação Física; alguns possuíam também especialização. Em relação à análise do regime de trabalho, os professores egressos possuíam carga horária de trabalho que variava entre trinta e quarenta horas semanais.

O instrumento utilizado na coleta de dados foi a entrevista semi-estruturada, realizada com o auxílio do uso de um gravador portátil, posterior à assinatura do termo de consentimento e livre esclarecido dos entrevistados. Após a coleta, as informações obtidas nas entrevistas foram transcritas para retornar aos entrevistados que puderam confirmar as informações e consentir o seu uso na pesquisa. A duração média das entrevistas realizadas foi de 20 minutos.

Após a realização de cada entrevista, houve a etapa de "transcriação", quando as entrevistas foram reescritas procurando respeitar as normas gramaticais para tornar o texto mais elaborado. $\mathrm{Na}$ seqüência, foram devolvidas aos participantes do estudo para analisarem o conteúdo e confirmarem as informações. Alguns participantes realizaram correções gramaticais no texto, o que foi acatado e modificado prontamente pelo pesquisador, retornando novamente o texto aos participantes do estudo.

\section{RESULTADOS E DISCUSSÃO}

\subsection{As experiências pessoais com a prática esportiva e a educação física escolar: as pré-concepções de avaliação}

Tanto a experiência esportiva quanto as experiências relacionadas ao movimento humano, em geral advindas das aulas de Educação Física, podem influenciar o desenvolvimento do processo de formação profissional na área da Educação Física.

$\mathrm{Na}$ análise da experiência esportiva, verificou-se que ela foi determinante na escolha da profissão. Contudo, alguns professores egressos que possuíam experiência esportiva anterior à formação inicial apresentaram sentimento de repúdio e indignação em relação à avaliação do desempenho físico e técnico dos alunos.

Movimento, Porto Alegre, v.13, n. 02, p.55-76, maio/agosto de 2007. 
$\mathrm{Na}$ análise das experiências pessoais relacionadas à avaliação vivenciadas no ensino fundamental e médio, identificou-se que os professores egressos eram avaliados pelo rendimento físico e técnico que apresentavam, conforme pode ser observado no relato:

\begin{abstract}
Algumas coisas acabam marcando a vida da gente, eu lembro que existiam avaliações práticas, tínhamos que saber por exemplo no voleibol, dar saque, e a nota variava de acordo com os acertos, se errássemos um diminuiria a nota. Assim eram avaliadas as outras modalidades também, tínhamos que correr em volta do colégio na rua, e cada volta que déssemos em determinado tempo somava uma determinada nota.

(DIRCE, PROFESSORA EGRESSA)
\end{abstract}

Na tentativa de compreender melhor os fatores que influenciaram o processo de estruturação da prática pedagógica, especificamente das práticas avaliativas dos professores de Educação Física, investigou-se o processo de formação profissional desta área, a partir das experiências vivenciadas em relação à avaliação.

\title{
3.2 Experiências iniciais na formação em Educação Física:
}

a estruturação das práticas avaliativas

A formação inicial na opinião de Carreiro da Costa (1991) pode alterar ou reforçar, conforme as ações e direcionamentos teóricos e práticos, as representações que os estudantes internalizaram ao longo do tempo, sendo necessário analisar as experiências pessoais relacionadas à avaliação no ensino superior dos professores egressos.

$\mathrm{Na}$ análise das experiências pessoais relacionadas à avaliação no ensino superior, tanto os conteúdos, objetivos e métodos de ensino quanto às estratégias de avaliação privilegiavam os aspectos quantitativos através da análise do desempenho técnico e físico.

No caso da graduação em Educação Física, especialmente na modalidade de licenciatura, a intenção principal volta-se geralmente à formação de futuros professores, portanto, os conteúdos, objetivos, métodos de ensino e as estratégias de avaliação precisam contemplar as expectativas e necessidades dos futuros docentes.

Movimento, Porto Alegre, v.13, n. 02, p.55-76, maio/agosto de 2007. 
Apesar disso, verificou-se a partir das vivências na formação inicial em Educação Física dos participantes da investigação que, em muitos momentos, o desenvolvimento de competências voltadas à futura atuação profissional não era considerado como ponto central do processo de ensino e aprendizagem, mas ao contrário, a ênfase era no desenvolvimento de capacidades físicas e habilidades direcionadas exclusivamente à prática esportiva.

A origem militarista de propostas e culturas vindas do exterior relacionadas à Educação Física marcou os primeiros currículos dos cursos, sendo a maior parte da carga horária destinada às disciplinas relacionadas aos esportes, predominando o paradigma esportivo. A formação não era de professores, mas de preparadores físicos (BETTI, 1991).

Com o intuito de analisar as experiências adquiridas no ensino superior em relação à avaliação, apresentou-se necessário identificar os procedimentos e instrumentos adotados nas avaliações das diversas disciplinas que compõem o currículo do curso.

3.2.1 Procedimentos avaliativos vivenciados na formação inicial

Os procedimentos mais utilizados no processo de avaliação durante a formação inicial em Educação Física, foram provas teóricas e trabalhos nas disciplinas que abarcam conteúdos de essência teórica e provas práticas nas disciplinas esportivas ou práticas, como pode ser observado na fala: "Nas disciplinas práticas tiveram avaliação prática e teórica, nas outras disciplinas, avaliações teóricas com trabalhos e provas" (Cléo, professora egressa).

A utilização destes procedimentos avaliativos nos cursos de formação de professores revelou em primeiro momento o privilégio da análise quantitativa em detrimento da análise qualitativa, especialmente no que se refere às disciplinas que envolvem conteúdos esportivos e culturais.

O enfoque exclusivamente quantitativo, assim como a ênfase nos resultados obtidos em apenas alguns momentos avaliativos privilegiava o produto final em detrimento da reflexão voltada ao processo

Movimento, Porto Alegre, v.13, n. 02, p.55-76, maio/agosto de 2007. 
como um todo, construído ao longo do tempo nas relações educativas, conforme o relato:

Às vezes eles avaliavam o que você sabia na hora e não o que você veio aprendendo, adquirindo, não levavam em consideração se você estava bem ou não naquele dia da prova, se foi atleta e já dominava o conteúdo. (ESCOLÁSTICA, PROFESSORA EGRESSA)

De fato, apenas a análise do produto final torna-se insuficiente para observar a evolução individual do sujeito no decorrer do processo de ensino e aprendizagem. As indicações da própria LDB (Lei de Diretrizes e Bases da Educação Nacional) enfatizam a necessidade da incorporação do caráter contínuo e cumulativo nas práticas avaliativas.

A avaliação constitui-se, na maioria das vezes, segundo Fensterseifer (1998) em instrumento para verificação da capacidade de memorização dos alunos. Com isso, o professor não utiliza o resultado das avaliações para interpretar, mas somente para verificar.

A maioria dos cursos de Educação Física, na opinião de Oliveira (1985), baseia-se na educação reprodutora, conformista, priorizando o aspecto técnico no processo de ensino e aprendizagem em detrimento do aspecto pedagógico-metodológico.

O próprio aluno acaba se acomodando, conforme Fensterseifer (1998), diante das incoerências do processo ao qual é submetido e que acaba prejudicando a sua própria formação, fazendo o que o professor exige, independentemente das suas necessidades e interesses.

A análise das experiências pessoais acerca da avaliação no ensino superior envolve tanto a forma como o acadêmico foi avaliado quanto as discussões realizadas sobre a temática durante o período de formação.

3.2.2 Discussões na formação inicial sobre a temática

$\mathrm{Na}$ análise das oportunidades de discussão sobre a temática em questão na formação inicial em Educação Física, os professores

Movimento, Porto Alegre, v.13, n. 02, p.55-76, maio/agosto de 2007. 
egressos destacaram a insuficiência de discussões sobre o assunto durante todo o curso de graduação, como pode ser observado nas falas:

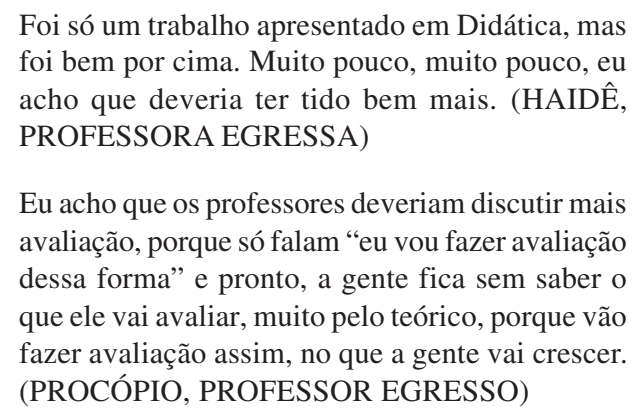

Foi só um trabalho apresentado em Didática, mas foi bem por cima. Muito pouco, muito pouco, eu acho que deveria ter tido bem mais. (HAIDÊ, PROFESSORA EGRESSA)

$\mathrm{Eu}$ acho que os professores deveriam discutir mais avaliação, porque só falam "eu vou fazer avaliação dessa forma" e pronto, a gente fica sem saber o que ele vai avaliar, muito pelo teórico, porque vão fazer avaliação assim, no que a gente vai crescer. (PROCÓPIO, PROFESSOR EGRESSO)

Esses comentários refletem o fraco impacto (CRUM, 1993) da formação inicial na estruturação da prática pedagógica, na qual está incluído o processo de avaliação ou as práticas avaliativas a serem implantadas pelo futuro profissional de Educação Física.

As práticas avaliativas constituem-se parte integrante do processo de ensino que será desenvolvido cotidianamente pelo futuro professor de Educação Física, o desenvolvimento do conteúdo deve ser preocupação de todo o corpo docente nas mais diversas disciplinas do curso de formação inicial em Educação Física, já que cada disciplina pode contribuir com um enfoque ou ponto de vista diferente nas discussões pedagógicas.

Ao contrário, a partir do momento em que o curso ignora a necessidade destas discussões, os futuros professores podem apresentar imensas dificuldades na implementação do processo avaliativo ao ingressar no mercado de trabalho.

Há poucas razões, de acordo com Crum (1993), para manter grandes expectativas quanto ao impacto da formação de professores, visto que muitos cursos sofrem de falta de consistência, sem uma cultura técnica partilhada entre os docentes e com confusão de ideologias em relação à própria Educação Física, e dificilmente serão instrumentos capazes de conduzir os profissionais a uma concepção claramente orientada para o ensino.

Movimento, Porto Alegre, v.13, n. 02, p.55-76, maio/agosto de 2007. 
Considerando que as experiências vivenciadas no período de formação inicial podem ser internalizadas e posteriormente reproduzidas no cotidiano educacional através da prática pedagógica, torna-se primordial aos cursos de graduação a realização de reflexões e discussões constantes acerca dos conteúdos que estão norteando a preparação para a docência.

A probabilidade de que os estudantes coloquem em prática os procedimentos que experienciaram, na opinião de Baggio (2000), é muito maior que daqueles que adquirem conhecimento apenas através de leituras ou na participação de cursos/palestras/ conferências.

\subsubsection{Impacto da formação inicial na estruturação das práticas avaliativas}

Sendo a formação inicial em Educação Física um curso preocupado com a capacitação dos futuros profissionais, suas ações precisam voltar-se no sentido de colaborar com a estruturação das práticas pedagógicas e, conseqüientemente, do processo de avaliação. Há necessidade de que durante esse processo sejam oportunizadas atividades de simulações ou até mesmo vivências de situações que os futuros professores enfrentarão na realidade do mercado de trabalho da área em que o processo avaliativo será presente e constante, assim como para facilitar este processo torna-se necessário formar profissionais capazes de analisar criticamente as situações de ensino e aprendizagem, adaptando-as e incorporando-as ao seu conhecimento.

No que diz respeito à análise do impacto da formação inicial no processo de estruturação das práticas avaliativas, os professores egressos consideraram a experiência profissional como o fator que mais influenciou ou contribuiu para a estruturação das práticas avaliativas, como podem ser observado nos seguintes relatos:

Quando comecei a trabalhar com a Educação Física já
me questionava como deveria avaliar, pois acredito ter
chegado ao final do curso na faculdade sem saber como
avaliar o aluno. No começo avaliava desempenho,
porém comecei a sentir-me frustrada porque via inú-
meros alunos frustrados também. Com o decorrer do
tempo, fui lendo, me informando, conversando com

Movimento, Porto Alegre, v.13, n. 02, p.55-76, maio/agosto de 2007. 


\section{Astigos Originais}

os professores e fui mudando. A visão que eu tinha da Educação Física também mudou. Hoje estou sempre procurando novas coisas para avaliar porque a questão da avaliação é um problema em todas as disciplinas. (DIRCE, PROFESSORA EGRESSA)

A própria experiência profissional, as tentativas a cada ano, depende muito da turma também. As leituras e discussões nas reuniões pedagógicas. (DORA, PROFESSORA EGRESSA)

Esta situação também foi encontrada nos estudos de Scherer (2000) sobre o conhecimento pedagógico dos professores de Educação Física, evidenciando que a experiência docente parece ser a principal fonte de conhecimento para a prática cotidiana do professor de Educação Física, a partir da qual durante a sua trajetória profissional, ele modifica suas estratégias de ação sustentadas, principalmente na reflexão sobre o seu cotidiano.

A entrada nas escolas e o contato com a prática diária da Educação Física, em conjunto com a falta de consistência dos cursos de formação inicial, de acordo com Crum (1993), afetam fortemente as concepções dos professores.

Ao analisar as influências e contribuições do curso de formação inicial na estruturação das práticas avaliativas dos participantes da investigação, verificou-se que estas foram consideradas insuficientes e pouco consistentes, tendo em vista a relevância do tema na área de atuação da Educação Física. Ao contrário, em muitos casos a formação inicial influenciou de forma negativa no que se refere à estruturação das práticas avaliativas, já que as experiências foram consideradas prejudiciais ao processo de ensino e aprendizagem, e os professores não gostariam de repeti-las ou incorporá-las em sua prática pedagógica.

Identificou-se, através dos depoimentos dos participantes da investigação, a despreocupação do curso de formação inicial em Educação Física em desenvolver conhecimentos sobre o processo avaliativo, já que foram relatadas poucas discussões relacionadas ao tema e realizadas apenas na disciplina de Didática. Assim, as experiências que os futuros profissionais vivenciaram em relação às

Movimento, Porto Alegre, v.13, n. 02, p.55-76, maio/agosto de 2007. 
práticas avaliativas centraram-se nos exemplos dos próprios docentes formadores, através dos sistemas de avaliação que implementaram.

Observou-se também que as oportunidades de desenvolver aprendizagens sobre avaliação apresentaram-se restritas, pelo fato de que, nas próprias atividades propostas e desenvolvidas pelo curso, que têm por objetivo fornecer aos professores em formação experiências próximas da realidade do mercado de trabalho, como os projetos de extensão, pesquisa e os estágios nos quais, os futuros profissionais chegam a desempenhar até mesmo funções de docência. A atividade de avaliar não é oportunizada ou permitida, o que dificulta imensamente o desenvolvimento de conhecimentos para a estruturação das futuras práticas avaliativas, como pode ser observado na fala:

\begin{abstract}
Eu acredito que isso deveria ser mais bem discutido... para se chegar num consenso, para se ter claro para o aluno que está saindo da graduação alguns encaminhamentos, alguns meios para ele utilizar isso quando for um profissional. (EVANDRO, PROFESSOR EGRESSO)
\end{abstract}

Este contexto em relação à discussão da avaliação existe, na opinião de Fensterseifer (1998), porque os professores não estão seguros da forma como avaliam seus alunos. Logo, não há interesse em utilizá-la; o único foco de discussão está relacionado ao tipo de instrumento de avaliação que será utilizado, mas geralmente prevalece o que os professores determinam.

Além da experiência profissional, outro fator considerado relevante no processo de estruturação das práticas avaliativas foi a formação continuada. De fato, quando o professor continua sua formação em cursos de pós-graduação, já traz consigo subsídios da realidade escolar em que atua que contribuem para as discussões sobre o assunto. Ao contrário, durante o curso de formação inicial as reflexões são muitas vezes meras aproximações com o real. Na formação continuada, o professor busca pontualmente resolver ou, discutir suas dúvidas advindas da própria prática pedagógica com reflexões mais consistentes do que no período de formação inicial.

A formação inicial em Educação Física necessita na opinião de Crum (1993), atingir a coesão conceitual, já que o desacordo

Movimento, Porto Alegre, v.13, n. 02, p.55-76, maio/agosto de 2007. 


\section{Astigos Originais}

Evandra Hein Mendes, et al.

conceitual na formação de professores é mais regra do que exceção. Para tanto, são necessários diálogos regulares entre os membros do corpo docente, liderança forte e um empenho coletivo.

Além disso, de acordo com Carreiro da Costa (1991), os professores não podem se eximir da responsabilidade sobre o estado atual da formação inicial em Educação Física, mas os professores enquanto agentes socializadores podem contribuir através da sua postura profissional para reforçar ou quebrar o ciclo de reprodução de certas idéias na Educação Física.

3.3 As características práticas avaliativas na educação física

Para analisar as relações da trajetória pessoal e o processo de estruturação das práticas avaliativas implementadas pelos professores egressos do curso de formação inicial em Educação Física da UNIOESTE, investigou-se as suas opiniões acerca da concepção, objetivos, procedimentos e número de avaliações e dificuldades enfrentadas.

\subsubsection{Concepções de avaliação na Educação Física Escolar}

$\mathrm{Na}$ análise das concepções de avaliação, identificou-se que os professores egressos compreendiam a avaliação tanto como mensuração, acompanhamento da construção e evolução dos conhecimentos quanto de incentivo à participação nas aulas de Educação Física.

A concepção de avaliação, enquanto mecanismo de mensuração, volta-se aos pressupostos da tendência tradicional de avaliação. A incorporação desta tendência na prática pedagógica do professor, conforme Souza (1993), privilegia a verificação quantitativa da extensão da retenção de conhecimentos.

Os professores egressos, apesar de conceituarem avaliação como medida, demonstraram um sentimento de repúdio muito intenso em relação à tendência clássica, conforme o relato: "As pessoas são diferentes e às vezes você aplica uma prova igual pra todo mundo... então, é difícil avaliar." (EVANDRO, PROFESSOR EGRESSO)

Movimento, Porto Alegre, v.13, n. 02, p.55-76, maio/agosto de 2007. 
Apesar disso, justificavam a adoção dos procedimentos de avaliação apenas pela análise da participação dos alunos e pela auto-avaliação, fato que esboça características da tendência humanista-reformista, já que na tomada desta postura, de acordo com Souza (1993) observa-se a intenção de realizar avaliação qualitativa, através de permanentes reflexões individuais, bem como a tentativa de evitar qualquer padronização de produtos da aprendizagem. Entretanto, o caráter qualitativo e participativo caracteriza-se pela informalidade e pouca consistência.

O desempenho do professor, de acordo com Santos (1997), é grandemente dependente de modelos de ensino internalizados ao longo de sua vida como estudante. Da mesma maneira, Soriano e Winterstein (2004), ao realizarem um estudo sobre a constituição da intervenção profissional em Educação Física, reconhecem alguns fatores peculiares da socialização profissional, anterior à própria graduação e que acompanham o profissional durante sua inserção no universo do mercado de trabalho e se transformam em axiomas que começam a compor as representações dos profissionais de Educação Física, orientando os valores, as prioridades, as formas de definir conteúdos e ações.

Alguns professores egressos apresentaram concepções de avaliação voltadas à análise da construção e evolução dos conhecimentos. A concepção e os conceitos voltavam-se aos pressupostos da tendência humanista-reformista de avaliação, que preconiza uma perspectiva processual de avaliar (OLIVEIRA, 1985).

A preocupação central da avaliação direcionava-se aos aspectos internos do indivíduo, especialmente os psicológicos. Indícios de intencionalidade de efetivação desta tendência nas práticas avaliativas foram verificados nos relatos:

É medir a evolução do indivíduo, sem comparar com
o outro, não se deve fazer comparações, respeitar as
individualidades, só que respeitar as individualidades
não é deixar que ele permaneça no mesmo patamar,
ele precisa evoluir, precisa melhorar.
(CATARINA, PROFESSORA EGRESSA)

Movimento, Porto Alegre, v.13, n. 02, p.55-76, maio/agosto de 2007. 


\section{Astigos Originais}

Evandra Hein Mendes, et al.

Avaliação pra mim, é ver o quanto o aluno melhorou ou não, a partir das aulas que eu estou dando. (CLÉO, PROFESSORA EGRESSA)

Tanto a forma como o processo de avaliação são compreendidos quanto à maneira como o ato avaliativo é incorporado na prática pedagógica da Educação Física; possuem estreitas relações com a intencionalidade do professor quando o desenvolve.

Os objetivos da avaliação são selecionados pelos docentes a partir das concepções já elaboradas ao longo do processo de construção dos conhecimentos, tanto no que se refere às práticas avaliativas, quanto da própria área da Educação Física e da educação como um todo.

\subsubsection{Objetivos de avaliação na Educação Física Escolar}

$\mathrm{Na}$ análise dos objetivos da realização de avaliações na Educação Física escolar, verificou-se que os professores egressos, pretendiam estimular a participação dos alunos nas aulas, como pode ser observado nas falas:

Os meus objetivos são a participação, que é o principal, dentro disso tem alguns itens, principalmente o respeito. O principal é o movimento em si, o aluno tem que participar da aula. (EUCLIDES, PROFESSOR EGRESSO)

Se você não avaliar, os alunos não participam, então essa questão da avaliação é necessária, porque dá um estímulo diferente para eles, porque na nossa área é complicado de trabalhar. (CLEONICE, PROFESSORA EGRESSA)

Ao perceber a preocupação dos professores de Educação Física com o desenvolvimento global do aluno nas aulas, de modo a a participação e a conscientização, Pereira (citado por BRANCHER e NASCIMENTO, 2003) ressalta a necessidade de melhorar a estruturação das aulas no sentido de os alunos terem o máximo de proveito. Os motivos ou objetivos que subsidiam as práticas avaliativas norteiam, conseqüentemente, os outros aspectos envolvidos neste processo, nomeadamente os procedimentos, instrumentos e o número de avaliações.

Movimento, Porto Alegre, v.13, n. 02, p.55-76, maio/agosto de 2007. 


\title{
3.3.3 Procedimentos de avaliação na Educação Física Escolar
}

No que se refere aos procedimentos de avaliação implementados pelos professores egressos, verificou-se que estes priorizavam a utilização da observação para avaliar a participação e a realização de trabalhos escritos, conforme os relatos:

\begin{abstract}
Jamais avaliaria desempenho, para mim ele precisa entender, saber como é, conhecer fundamentos do jogo e principalmente poder participar do jogo. Procuro fazer com que ele conheça um determinado esporte, como um todo. A participação e o interesse que eles têm em aprender precisam ser avaliados, o comportamento inclusive, porque a educação é um todo, o papel da Educação Física deve ser também de educar. (DIRCE, PROFESSORA EGRESSA)
\end{abstract}

Resultados semelhantes foram encontrados nos estudos de Farias, Shigunov e Nascimento (2002), quando investigaram a prática pedagógica dos professores de Educação Física em Florianópolis, Santa Catarina e identificou que a avaliação realizada nas escolas era bastante subjetiva, pois na maioria das vezes os alunos eram avaliados apenas pela participação nas atividades propostas pelos docentes.

Os procedimentos utilizados pelos professores para avaliar, na opinião de Fensterseifer (1998), devem buscar o que para eles é importante e o que procuram analisar no processo, através da escolha dos instrumentos que possam fornecer maior número de dados, da mesma forma os dados mais significativos devem ser selecionados, elencando os critérios de satisfação e insatisfação com os resultados da análise. De fato, a própria história da área subsidia estas interpretações na opinião de Betti (1991), visto que ela foi marcada desde o início do seu surgimento pelo caráter disciplinador, calcado em princípios militaristas de desempenho físico, técnico e competitivo.

Em contrapartida, apesar de a concepção disciplinadora ser incorporada pelos profissionais e identificada perante o senso comum, a Educação Física evoluiu como área de conhecimento, especialmente no que diz respeito à sua vinculação com as outras áreas,

Movimento, Porto Alegre, v.13, n. 02, p.55-76, maio/agosto de 2007. 
tanto a da saúde quanto a educacional em geral, incorporando outros conteúdos para serem desenvolvidos nas aulas e analisados no processo avaliativo, como por exemplo, os relacionados à aquisição e incorporação de hábitos de vida saudável, ou ainda, os conhecimentos culturais do movimento humano que envolve os esportes, a dança, a ginástica e vivências corporais em geral.

Contudo, identificou-se uma grande probabilidade de que estes conteúdos não estavam sendo desenvolvidos nas aulas de Educação Física, já que os professores egressos não demonstraram intenção de avaliá-los e afirmavam avaliar somente os aspectos voltados à dimensão comportamental do aluno a partir da observância única e exclusiva da participação nas aulas.

A Educação Física sofre há muito tempo, de acordo com Crum (1993), com a falta de motivação e empenho dos professores voltados ao ensino. Em consequiência disso, há ausência de aprendizagem nas aulas da disciplina, que conseqüentemente não atinge o perfil de uma atividade de ensino-aprendizagem relevante.

3.3.4 Quantidade de avaliações realizadas por bimestre na Educação Física Escolar

A quantidade de avaliações realizadas no processo de ensino pelo professor pode se caracterizar como um indicador da concepção de avaliação que ele possui e a coerência do sistema implementado.

No que diz respeito à quantidade de avaliações oferecidas aos alunos por bimestre, observou-se que os professores egressos realizavam apenas observações diárias.

A tendência de avaliação progressista preconiza que a avaliação precisa apresentar caráter contínuo e cumulativo privilegiando a análise qualitativa das informações obtidas no decorrer do processo de ensino e aprendizagem (SOUZA, 1993).

Piletti (2000) comenta que o processo avaliativo deve começar no primeiro dia de aula, para adquirir informações diretas, imprescindíveis e valiosas ao planejamento das aulas, conjugando as três modalidades de avaliação (diagnóstica, formativa e somativa).

Movimento, Porto Alegre, v.13, n. 02, p.55-76, maio/agosto de 2007. 


\section{CONSIDERAÇÕES E SUGESTÕES}

O processo de estruturação das práticas avaliativas dos professores de Educação Física pode ser comparado ao processo de metamorfose: é lento e demorado, impregnado de incertezas e dúvidas, e que se inicia já na infância com as constantes experiências relacionadas à avaliação. As experiências pessoais adquiridas tanto no âmbito escolar quanto no extra-escolar desenvolvem préconcepções de avaliação (lagarta), que podem permanecer e se fortalecer ou se modificar durante o transcorrer do curso de formação inicial em Educação Física (casulo), onde ocorre um processo de modelação. Com a saída do curso de formação inicial e a entrada no mercado de trabalho acontece o impacto com a cultura docente (os primeiros vôos da borboleta), que gera reflexões e re-elaborações da prática pedagógica até então idealizada, especificamente no que se refere ao processo de avaliação.

Para identificar a influência das pré-concepções (fase de lagarta) no processo de estruturação das práticas avaliativas dos participantes da investigação, analisaram-se as experiências com a prática esportiva e aquelas adquiridas no ensino fundamental e médio.

Em relação às experiências adquiridas com a prática esportiva, estas pareceram ter sido muito significativas na vida de todos aqueles que as vivenciaram, sendo determinantes na escolha da profissão de professor de Educação Física. Entretanto, tanto os sujeitos que vivenciaram a prática esportiva sistematizada, quanto os que não a vivenciaram adotaram sistemas e tendências diferentes de avaliação.

Quanto às experiências adquiridas nas aulas de Educação Física no ensino fundamental e médio, os professores egressos sofreram experiências negativas com o processo de avaliação, traduzidas especialmente na área da Educação Física pela aferição do desempenho físico e técnico.

Contudo, identificou-se uma tendência de diminuição da intenção dos professores de Educação Física de avaliarem o desempenho nas aulas ao longo dos anos, visto que foram vivenciadas pelos professores egressos, mas estes não as realizam com seus alunos.

Movimento, Porto Alegre, v.13, n. 02, p.55-76, maio/agosto de 2007. 
Em relação às experiências adquiridas na formação inicial em Educação Física, os participantes da investigação foram avaliados através de provas teóricas e trabalhos nas disciplinas que abarcam conteúdos de essência teórica e provas práticas nas disciplinas esportivas ou práticas. $\mathrm{O}$ enfoque era quantitativo, assim como a ênfase era nos resultados obtidos em apenas alguns momentos avaliativos, privilegiava-se o produto final em detrimento da reflexão voltada ao processo como um todo.

$\mathrm{Na}$ análise das oportunidades de discussão sobre a temática em questão na formação inicial em Educação Física, os professores egressos destacaram a insuficiência de discussões sobre o assunto durante todo o curso de graduação.

Para analisar as características das práticas avaliativas implementadas pelos professores egressos do curso de Educação Física da UNIOESTE (primeiros vôos da borboleta), investigou-se as concepções, os objetivos, os procedimentos, a quantidade e as dificuldades encontradas durante o desenvolvimento do processo de avaliação nas aulas de Educação Física.

No que diz respeito às concepções de avaliação dos professores egressos, constatou-se que a maioria ainda compreendia a avaliação como medida e não como instrumento de acompanhamento da construção e evolução do conhecimento. Poucos percebiam o valor da avaliação como feedback para o professor e aluno. Quanto aos objetivos da avaliação dos professores egressos, estes pretendiam apenas estimular a participação nas aulas de Educação Física. No que se refere aos procedimentos de avaliação dos professores egressos, estes utilizavam na maioria das vezes somente a observação para analisar a participação nas aulas de Educação Física. Em relação à quantidade de avaliações realizadas bimestralmente pelos professores egressos, estas eram realizadas diariamente através de observações.

No que diz respeito aos aspectos que mais influenciaram efetivamente o processo de estruturação das práticas avaliativas na opinião dos próprios professores egressos, a maioria considerou a própria experiência profissional e a formação continuada, através de trocas de informações com colegas de profissão e leituras individuais em detrimento das aprendizagens desenvolvidas no curso de formação

Movimento, Porto Alegre, v.13, n. 02, p.55-76, maio/agosto de 2007. 
inicial. Da mesma forma, as discussões realizadas no período de formação inicial sobre a temática foram consideradas insuficientes ou inexistentes. Sendo assim, poucos professores egressos acreditaram que o curso de graduação contribuiu efetivamente para a estruturação das práticas avaliativas e muitas vezes serviram até mesmo como modelo negativo a ser evitado na prática pedagógica escolar.

Diante das reflexões apresentadas, identifica-se que a avaliação é a fonte de muitos problemas evidenciados no contexto educacional em todos os níveis de ensino (fundamental, médio e superior), que afeta tanto a vida dos estudantes quanto a dos professores, já que ambos estão envolvidos diretamente no processo de avaliação da aprendizagem.

Neste sentido, aspectos relacionados à forma como o professor constrói e desenvolve suas práticas avaliativas, estão envolvidos no processo de compreensão de ensino, visto que nele se encontram subjacentes as concepções de homem, mundo e da própria área da Educação Física.

Ao terminar este estudo, tem-se a sensação de "incompletude" que tanto é angustiante como estimulante, já que ao final estabeleceram-se algumas certezas e muitas dúvidas.

Apesar de a abordagem adotada na investigação ter contribuído para o surgimento de inúmeras informações sobre o processo de avaliação adotado tanto nos cursos de formação inicial como na prática pedagógica escolar, sugere-se a realização de outros estudos que busquem melhor esclarecer os processos de estruturação das características da intervenção profissional quando da inserção no mercado de trabalho, identificando como o professor seleciona as estratégias de ação, quais e por que conteúdos, modelos e concepções de ensino abordados na formação inicial são adotados e incorporados ou descartados, ou ainda, como acontece a reorganização do que é idealizado antes do início da atuação profissional e quando esta se efetiva, ou seja, o processo de socialização profissional.

Percebe-se após a realização desta investigação, que na busca de uma intervenção profissional melhor, especialmente no que diz respeito ao processo de avaliação, torna-se difícil encontrar a solução

Movimento, Porto Alegre, v.13, n. 02, p.55-76, maio/agosto de 2007. 


\title{
74 Astigos Originais
}

Evandra Hein Mendes, et al.

imediata de todos os problemas verificados. Em contrapartida, é preciso assumir uma atitude de modéstia, de humildade, de perseverança e paciência com a convicção de que não há problemas que não possam ser resolvidos, mesmo que a princípio não pareça.

\begin{abstract}
Metamorphoses in the evaluation in physical education: from the initial formation to the school pedagogic practice

Abstract: The structuring process of the pedagogic practice and specifically the evaluation practice at physical education subject, it can be influenced as the evaluation in high and elementary school, as the individue tries at the initial formation or with the entrance at the job market and the impact with the teaching culture which is already installed. At this perspective, this investigation analyzed the structuring process at the evaluation practice at the physical education subject at school. The results revealed the weak impact of the initial formation at the structuring process, it was more decisive the professional experience came from the own educational reality.

Keywords: Evaluation. Learning. Physical education. Faculty. Professional practice.
\end{abstract}

Las metamorfosis en la evaluación en la
educación física: de la formación inicial a la
práctica pedagógica escolar
Resumen: el proceso de la estructuración de la
práctica pedagógica y específicamente la práctica
de la evaluación al asunto de educación física,
puede influenciarse como la evaluación en la escuela
alta y elemental, como las pruebas del individuo a la
formación inicial o con la entrada al mercado del
trabajo y el impacto con la cultura instrucción que ya
se instala. Esta investigación analizó el proceso de
la estructuración a la práctica de la evaluación al
asunto de educación físico en la escuela a esta pers-
pectiva. Los resultados revelaron el impacto débil
de la formación inicial al proceso de la estructuración
era más firme la experiencia profesional vino de la
propia realidad educativa.
Palabras clave: Evaluación. Aprendizaje.
Educación física. Docentes. Prática profesional.

Movimento, Porto Alegre, v.13, n. 02, p.55-76, maio/agosto de 2007. 


\section{REFERÊNCIAS}

BAGGIO I. C. A prática curricular do CEFD/UFSM e as competências para a promoção da autonomia. 2000. Dissertação (Mestrado) - UFSM, Santa Maria 2000 Programa de Pós-Graduação em Ciência do Movimento Humano, UFSM, 2000.

BETTI, M. Educação física e sociedade. São Paulo: Movimento, 1991.

BOGDAN, R. C.; BIKLEN, S. K. Investigação qualitativa em educação: uma introdução à teoria e métodos. Porto: Porto Editora, 1994.

BONNIOL, J. J. Modelos de avaliação: textos fundamentais com comentários. Tradução de Cláudia Schilling. Porto Alegre: Artmed, 2001.

BRANCHER, E. A.; NASCIMENTO, J. V. Estruturação da prática pedagógica dos professores do curso de graduação em Educação Física: um estudo de caso. In: NASCIMENTO, J. V.; LOPES, A. S. (org.). Investigação em Educação Física: primeiros passos, novos horizontes. Londrina: Midiograf, 2003.

BRASIL. Ministério da Educação e Cultura. Parâmetros Curriculares Nacionais. Brasília, DF, 2004.

BRATIFISCHE, S. A. Avaliação em Educação Física: um desafio. Revista da Educação Física/UEM, Maringá, v.14, n. 2, p. 21-31, 2003.

CANFIELD, M. S. Planejamento das aulas de Educação Física: é necessário? In: Isto é Educação Física. Santa Maria: JtC, 1996.

CARREIRO DA COSTA, F. Formação inicial de professores de Educação Física: problemas e perspectivas. Boletim da Sociedade Portuguesa de Educação Física, Porto, v.1, p. 21-34, 1991.

CARREIRO DA COSTA, F. O sucesso pedagógico em educação física. Estudo das condições e factores de ensino-aprendizagem associados ao êxito numa unidade de ensino. Lisboa: FMH/Cruz Quebrada, 1995.

CRUM, B. A crise de identidade da Educação Física: ensinar ou não ser, eis a questão. Boletim da Sociedade Portuguesa de Educação Física, Porto, v. 7, n. 8, p.133-148, 1993.

FARIAS, G. O., SHIGUNOV, V.; NASCIMENTO, J. V. do. O percurso profissional dos professores de Educação Física nas escolas. In: SHIGUNOV, V.; SHIGUNOV NETO, A. Educação Física: conhecimento teórico x prática pedagógica. Porto Alegre: Mediação, 2002.

FENSTERSEIFER, A. Avaliação da aprendizagem no ensino superior. Florianópolis: Editora UFSC, 1998.

Movimento, Porto Alegre, v.13, n. 02, p.55-76, maio/agosto de 2007. 
GONÇALVES, C. Estudo do pensamento dos alunos sobre o processo de formação em Educação Física. Boletim da Sociedade Portuguesa de Educação Física, Porto, v.15, n. 16, p. 99-112, 1997.

HOFFMANN, J. M. L. Avaliação, mito e desafio: uma perspectiva construtivista. 28. ed. Porto Alegre: Mediação, 2000.

LEAL, J.; CARREIRO DA COSTA, F. A atitude dos alunos face à escola, à Educação Física a alguns comportamentos de ensino do professor. Boletim da Sociedade Portuguesa de Educação Física, Porto, v.15, n. 16, p. 113-125, 1997.

OLIVEIRA, V. M. de. Educação Física humanista. Rio de Janeiro: Ao livro técnico, 1985.

PACHECO, J. A.; FLORES, M. A. Formação e avaliação de professores. Portugal: Porto Editora, 1999.

PILETTI, C. Didática geral. 23. ed. São Paulo: Ática, 2000.

ROMBALDI, R. M. A avaliação e sua importância. In: CANFIELD, M. S. (org). Isto é Educação Física. Santa Maria: JtC,1996.

SANTOS, L. L. de C. P. Formação do professor e pedagogia crítica. In: FAZENDA, I. C. A. (org). A pesquisa em educação e as transformações o conhecimento. Campinas: Papirus, 1997.

SCHERER A. O conhecimento pedagógico do professor de educação física na escola pública da rede estadual de ensino e sua relação com a prática docente. 2000. Dissertação (Mestrado). UFRGS, Porto Alegre, 2000 Curso de Pós-Graduação em Ciência do Movimento Humano.

SORIANO, J. B.; WINTERSTEIN, P. J. A constituição da intervenção profissional em Educação Física: interações entre o conhecimento "formalizado" e as estratégias de ação. Revista Brasileira de Educação Física da USP, São Paulo, v.18, n. 4, p. 315-332, 2004.

SOUZA, N. P. Avaliação na Educação Física. In: VOTRE, S. (org). Ensino e avaliação em Educação Física. São Paulo: Ibrasa, 1993.

Movimento, Porto Alegre, v.13, n. 01, p.13-37, janeiro/abril de 2007. 